\title{
Comparison of Different Covid-19 Vaccines Globally: An Overview
}

\author{
Asif Bilal ${ }^{1 *}$, Anisa Iftikhar ${ }^{1}$, Umer Ali $^{1}$, Nimra Naveed $^{2}$, Muhammad Imran Anjum $^{1}$, Urooj Fatima ${ }^{1}$, Iqra Akbar ${ }^{3}$, \\ Muhammad Saif-ur- Rehman ${ }^{4}$ and Muhammad Khuram Sajjad ${ }^{3}$
}

${ }^{1}$ Department of Zoology, University of Lahore, Pakistan

${ }^{2}$ Department of Zoology, Wildlife and Fisheries, University of Agriculture, Pakistan

${ }^{3}$ Department of Zoology, University of Sargodha, Pakistan

${ }^{4}$ Department of Cardiology, Shaikh Zayed Teaching Hospital, Pakistan

Submission: June 03, 2021; Published: June 11, 2021

*Corresponding author: Asif Bilal, Department of Zoology, University of Lahore, Pakistan

\begin{abstract}
It was 2012 when the first case of corona virus noticed by the Saudi Authorities which spread through the Asian countries, also flown to European countries. In 1960 revealed the presence of the corona virus when it was declared as the reason of common cold in human beings. On January 30, 2020, the WHO declared the COVID-19 outbreak a global health emergency. On March 11, 2020, the WHO declared COVID-19 a global pandemic. There are three brands of vaccines available that are Pfizer, Moderna and Johnson \& Johnson (Janssen). A mild difference may present as post vaccination effects. The Pfizer-BioNTech COVID-19 vaccine is based as mRNA and marketed as Comirnaty.

Pfizer reported a 91 percent efficacy rate after six months, while Moderna reported a 94 percent efficacy rate. Moderna, we are pioneering a class of medicines based on messenger RNA (mRNA). The Janssen COVID-19 Vaccine may not protect everyone. Mostly 2 doses of the vaccine are required to protect, and these are intramuscular injections. Its quantity would be changed in different age groups. Some common side effects include fatigue, headache, and pain in joints, fever, chills, and muscle pain. However, everyone should vaccinate for protection of corona virus disease.
\end{abstract}

Keywords: Vaccine; Covid-19; Pfizer; Moderna; Janssen; mRNA

\section{Introduction}

The year 1960 revealed the presence of the corona virus when it was declared as the reason of common cold in human beings. A study witnessed by Canada on about 500 persons contracting with flue, the analysis of pathogen sampled from these patients resulted in 3.6 percent HCo V-NL63, identified by a reliable PCR. The year 2002 had a final calendar which retained this virus as non-threatening to the life. The year 2003 witnessed an outbreak in Chinese Province Gaungdong, this outbreak flown to many neighboring counties and USA as well, this SARS (Severe Acute Respiratory Disease) caused fatal breathing mechanism malfunctioning leading to hundreds of deaths. Microbiologists found a new form of corona virus behind this disease. The situation became very critical so that WHO (World Health Organization) and CDC (Centre of Disease control) had to call emergency state. $60 \%$ of the flue patients were found positive for this deadly virus in Hong Kong. The investigation about the causative virus yielded that there is a strong ability in the virus to modify its genetic material promptly, which is just fatal to human life. COVID-19 is basically a respiratory disease, whose causative agent is a virus. The virus enters the respiratory tract through eyes, mouth and nose to dwell in the lungs eventually eradicates the pleural tissue of the lung leading the inability of the lungs to inhale and exhale the air.

\section{Background}

It was 2012 when the first case of corona virus noticed by the Saudi Authorities which spread through the Asian countries, also flown to European countries. Coronavirus disease 2019 (COVID-19) is an illness caused by a novel coronavirus called severe acute respiratory syndrome coronavirus 2 (SARS-CoV-2; formerly called Covid-19) which was first identified as an outbreak 
of respiratory illness cases in Wuhan City, Hubei Province, China. It was initially reported to the World Health Organization (WHO) on December 31, 2019. On January 30, 2020, the WHO declared the COVID-19 outbreak a global health emergency. On March 11, 2020, the WHO declared COVID-19 a global pandemic.

An access to safe and effective vaccines is needed to end the COVID-19 pandemic, so it is hugely encouraging to see so many vaccines proving and going into development. WHO is working tirelessly with partners to develop and manufacture safe and effective vaccines. Safe and effective vaccines are a game-changing tool. This scenario demands the development of a presumptive vaccine which may provide immunity against all current and new evolving coronavirus strains. More than 100 companies had been working on Corona vaccine across the globe. More than one billion doses of coronavirus vaccines have been administered, in 178 countries worldwide.

A range of different vaccines is being used to reduce people's chances of getting virus, needing hospital treatment or dying. The three vaccines pacemaker are those developed by Pfizer-BioNTech, Moderna and Oxford-AstraZeneca. These have been approved for use in the UK, Europe and the US. Results from large-scale trials on two new vaccines have also been presented recently. The work by Janssen, which is owned by Johnson \& Johnson, and Novavax. There are other noteworthy vaccines, even if they are not being used in Europe and the US. The Sinovac, CanSino and Sinopharm vaccines have been developed by scientists in China and deals have signed with other countries in Asia and South America. Around one million people in China are reported to have been given the Sinopharm injection. The Sputnik V vaccine, developed by Russia's Gamaleya Research Centre, is also effective.

\section{Types of Covid-19 Vaccines}

There are three brands of vaccines available presently, effectively being injected for immunization against this pandemic. Pfizer, Moderna and Johnson (Janssen) All these vaccines are almost equally effective against the pandemic of COVID-19. They are all life saver up to 100. A mild difference may present as post vaccination effects.

\section{Pfizer-BioNTech}

The Pfizer-BioNTech COVID-19 vaccine (INN: tozinameran), is based as mRNA and marketed as Comirnaty. The vaccine's modRNA sequence is 4,284 nucleotides long [1]. It is approved that are used in people aged 12 and up to protect against infection with the SARS-CoV-2 virus, which causes COVID-19 [2]. It is approved for use in persons aged 12 and up by the FDA and some other authorities and the EMA for persons aged 16 and above, to protect against infection with the SARS-CoV-2 virus, which produces COVID-19 [2]. The vaccine was created by BioNTech, a German organization, with assistance from Pfizer, an American corporation, for clinical testing, logistics, and production [3]. The U.S. Food and Drug Administration (FDA) has issued an
Emergency Use Authorization (EUA) to permit the emergency use of the unapproved product, Pfizer-BioNTech COVID-19 Vaccine, for active immunization to prevent COVID-19 in individuals 12 years of age and older.

In addition to the mRNA molecule, the vaccination contains the inactive components listed here; ALC-0315, ALC-0159, CHOLESTROL, 1,2-distearoyl-sn-glycero-3-phosphocholine, monobasic potassium phosphate, $\mathrm{NaCl}$, sucrose, dibasic sodium phosphate dehydrate and water for injection [4]. In China, BioNTech has a development, marketing, and distribution partnership with Fosun Pharma, and the vaccine is informally known as the Fosun-BioNTechCOVID-19 vaccine [5,6]. The vaccination is administered through intramuscular injection in the form of frozen suspension. Before administration, it must be frozen to room temperature and diluted with normal saline [7]. It requires two doses that administered three weeks apart. It is made up of nucleoside-modified mRNA (modRNA) that encodes a mutant variant of SARS-full-length CoV-2's spike protein, which is encased in lipid nanoparticles [8]. Clinical studies began in April2020, and by November2020, the vaccine has entered phase III trials, with over 40,000 people engaging [8]. Mild to severe discomfort at the injection site, tiredness, muscle and joint pain, fever and headaches are the most typical side effects [9]. Serious side effects, such as allergic responses, have been recorded infrequently and no long-term consequences have been recorded $[2,10]$. The main outcomes of the trials will be monitored until August2021, while the secondary outcomes will be monitored until January 2023 Tran et al. [11]. The vaccine was the first COVID-19 vaccine to be approved for emergency use by a strict regulatory authority [12] and the first to be licensed for routine use [13]. The United Kingdom was the first country to approve its usage in an emergency in December 2020 [10].

It is legal to use in 84 countries, including the United States, the European Union, the United Kingdom, Ukraine, Israel, Brazil, Mexico, Japan, and Singapore [14]. Pfizer and BioNTech intended to produce around 2.5 billion doses in 2021 as of March30, 2021 [5]. BioNTech and Pfizer have agreed to pay around $\$ 3$ billion in advance purchase agreements to offer a licensed vaccine in the United States, the European Union, the United Kingdom, Japan, Canada, Peru, Singapore, and Mexico [11]. Because the vaccine must be maintained at extremely low temperatures, distribution and storage are logistical challenges. BioNTech and Pfizer are experimenting with a freeze-dried version that does not require ultra-cold storage.

\section{Moderna}

Moderna is a biotechnology company founded in 2010. At Moderna, we are pioneering a class of medicines based on messenger RNA (mRNA). Every cell in your body uses mRNA, which gives instructions to make the proteins your body needs. This affects many aspects of your biology, including health and disease. The Moderna COVID-19 Vaccine will be given to you as an injection 
into the muscle. The Moderna COVID-19 Vaccine vaccination series is 2 doses given 1 month apart. If you receive one dose of the Moderna COVID-19 Vaccine, you should receive a second dose of the same vaccine 1 month later to complete the vaccination series. This is a multidose vial which contains 10 doses of $0.5 \mathrm{~mL}$. One dose $(0.5 \mathrm{~mL})$ contains 100 micrograms of messenger RNA (mRNA) (embedded in SM-102 lipid nanoparticles). COVID-19 Vaccine Moderna is administered as a course of 2 doses $(0.5 \mathrm{~mL}$ each). It is recommended to administer the second dose 28 days after the first dose.

The Moderna COVID-19 Vaccine is an unapproved vaccine. In clinical trials, approximately 15,400 individuals 18 years of age and older have received at least 1 dose of the Moderna COVID-19 Vaccine. In an ongoing clinical trial, the Moderna COVID-19 Vaccine has been shown to prevent COVID-19 following 2 doses given 1 month apart. The duration of protection against COVID-19 is currently unknown.

There is a remote chance that the Moderna COVID-19 Vaccine could cause a severe allergic reaction. A severe allergic reaction would usually occur within a few minutes to one hour after getting a dose of the Moderna COVID-19 Vaccine. For this reason, your vaccination provider may ask you to stay at the place where you received your vaccine for monitoring after vaccination.

The Moderna COVID-19 Vaccine contains the following ingredients: messenger ribonucleic acid (mRNA), lipids (SM102, polyethylene glycol [PEG] 2000 dimyristoyl glycerol [DMG], cholesterol, and 1,2-distearoyl-sn-glycero-3-phosphocholine [DSPC]), tromethamine, tromethamine hydrochloride, acetic acid, sodium acetate trihydrate, and sucrose. The severe acute respiratory syndrome coronavirus 2 (SARS-CoV-2) first appeared in late 2019 and quickly spread over the world, forcing an international effort to speed up vaccine development. The relatively stable prefusion SARS-CoV-2 spike protein is encoded by the candidate vaccine mRNA-1273, entitled Moderna [15]. Vaccines are needed to protect those who are at high risk of complications from coronavirus disease 2019 (Covid-19). The mRNA-1273 vaccine is a lipid nanoparticle-encapsulated mRNAbased vaccination that encodes the full-length prefusion stable spike protein of SARS-CoV-2, the virus that causes Covid-19 [1618].

This phase 3 standardized, independent observer, placebocontrolled experiment was held at 99 multiple places around the United States. People at high risk of SARS-CoV-2 infection or its manifestations were given two intramuscular injections of mRNA$1273(100 \mathrm{~g})$ or placebo 28 days apart in a 1:1 ratio. A total of 30,420 participants were randomized between July 27,2020 , and October 23, 2020, with 15,210 individuals in each group receiving two doses of either placebo or mRNA-1273 (100g). The second dosage was given to almost 96 percent of the individuals. Common reasons for not receiving the second dose were withdrawal of consent (153 participants) and the detection of SARS-CoV-2 by
PCR before the administration of the second dose on day 29 (114 participants: 69 in the placebo group and 45 in the mRNA-1273 group) $[19,20]$.

\section{Johnson and Johnson's Jessen}

On February 2, 2021 the U.S. Nourishment and Sedate Organization issued and crises utilize authorization (EUA) for the third antibody for the avoidance of coronavirus illness 2019 (COVID-19) caused by extreme intense respiratory disorder coronavirus 2 (SARS-CoV-2). The EUA permits the Janssen COVID-19 Immunization to be disseminated within the U.S for utilize in peoples 18 a long time of age and more seasoned. Its formatting is by Janssen Biotech institute, a Janssen Pharmaceutical Company of Johnson and Johnson [21,22].

You are being offered the Janssen COVID-19 Vaccine to prevent Coronavirus Disease 2019 (COVID-19) caused by SARS-CoV-2. This Fact Sheet contains information to help you understand the risks and benefits of receiving the Janssen COVID-19 Vaccine, which you may receive because there is currently a pandemic of COVID-19. The Janssen COVID-19 Vaccine may prevent you from getting COVID-19. There is no U.S. Food and Drug Administration (FDA) approved vaccine to prevent COVID-19. Read this Fact Sheet for information about the Janssen COVID-19 Vaccine. Talk to the vaccination provider if you have questions. It is your choice to receive the Janssen COVID-19 Vaccine. The Janssen COVID-19 Vaccine is administered as a single dose, into the muscle. The Janssen COVID-19 Vaccine may not protect everyone [23-26].

The Janssen COVID-19 Vaccine is an unapproved vaccine. In an ongoing clinical trial, 21,895 individuals 18 years of age and older have received the Janssen COVID-19 Vaccine. The Janssen COVID-19 Vaccine includes the following ingredients: recombinant, replication-incompetent adenovirus type 26 expressing the SARS-CoV-2 spike protein, citric acid monohydrate, trisodium citrate dihydrate, polysorbate-80, sodium chloride, ethanol, 2-hydroxypropyl- $\beta$-cyclodextrin (HBCD) [27-30].

Protect from the coronavirus disease Covid-19 for the person of 18 years and older ages persons. FDA has authorized the emergency use of the Janssen COVID-19 Vaccine in individuals 18 years of age and older. You should not get the Janssen COVID-19 Vaccine if you had a severe allergic reaction to any ingredient of this vaccine [31-34].

\section{Common Side Effects}

Covid-19 vaccines are very effective but they also have some side effects. All these vaccines are 'reactogenic' means they cause effective change in immunity response. Different vaccines have different side effects. As vary according to their type. These are different covid-19 vaccination like Pfizer and 'Moderna' messenger RNA vaccine. One of the common side effect is soreness in the skin where injected the vaccine. Other common side effects include fatigue, headache, and pain in joints, fever, chills, and muscle pain. 
All these side effects are because of the immune system is instructing body to react in certain ways: it may increase blood flow so more immune cells can circulate, and it can also raise your body temperature to kill the virus. These side effects are the signs that the body's immune system is responding to the vaccine The most commonly side effects were pain at the time of injection site, Headache, Fatigue, and nausea etc. There were mostly side effects occurred within 1-2 days following vaccination and were mild to moderate in severity and lasted 1-2 days. Injection site reactions: pain, redness of the skin and swelling. General side effects: headache, feeling very tired, muscle aches, nausea, and fever. There are two main doses of covid-19 vaccine.

After 2 nd dose side effect shows more frequently. These side effects maybe last for 24 to 48 hours or can be more than a few days. There is limited experience with use of COVID-19 Vaccine Moderna in pregnant women: Animal studies do not indicate direct or indirect harmful effects with respect to pregnancy, embryo/ foetal development, parturition or post-natal development. Vaccine Moderna in pregnancy should only be considered when the potential benefits outweigh any potential risks for the mother and foetus.

Side effects of the vaccine are not frequent in young age people. People with older than 55 can get more strong side effects mentioned above. Children younger than 12 years of age have not yet received vaccines in clinical trials, so there is no evidence of side effects in children. There are some less common side effects reported for covid-19 including severe allergic reactions such as anaphylaxis and such as side effects lasting more than three days.

\section{Discussion}

We searched the databases for articles in which the authors discussed the efficacy and safety of various vaccines, as well as the incidence of adverse responses, by sex, age group, and gender. A total of 19 relevant papers were discovered and addressed throughout this book. As described throughout the essay, the present situation in the field of inventive capacity includes various technological improvements as well as the collection of knowledge and prior experiences in the pursuit of a more rapid path of the Research and Development process for new vaccines. It is clear that the COVID-19 outbreak puts societal pressure on researchers to find a cure. As a result of these elements resulting from the global public health emergency, it is envisaged that the Research and Development procedures for new pharmaceuticals, including new vaccinations, will be redirected, especially during pandemics. Learning also helps to optimize and speed development paths in the search for cures for diseases that are being researched. Antibodies are discovered six months after vaccination in those who have been vaccinated, with only minor reduction. This is not to say they vanish after six months; it's just the information we know. Pfizer reported a 91 percent efficacy rate after six months, while Moderna reported a 94 percent efficacy rate. Antibodies were still high 70 days after immunization, despite the fact that the Johnson \& Johnson vaccine hasn't been around long enough to provide long-term data. There are some side effects of these vaccines which are discussed above briefly for example allergic reactions, fever, pain and sometimes vomiting. Animal studies show that the vaccine Moderna has no direct or indirect negative effects on pregnancy, embryo/foetal development, parturition, or post-natal development in pregnant people. Vaccine Moderna should only be explored during pregnancy if the possible advantages outweigh the hazards to the mother and fetus. As we study all the types of vaccine, and it is concluded that Pfizer is more efficient than others while Johnson \& Johnson vaccine is lower efficient than others. National authorities and international bodies, including WHO, are closely monitoring for any unexpected side effects following COVID-19 vaccine use.

\section{References}

1. Nikhra V (2021) Evolving patterns in covid-19: the virus, its variants and infectivity-cum-virulence. Biomedical Journal of Scientific \& Technical Research 33(2): 25712-25722.

2. Moustsen-Helms IR, Emborg HD, Nielsen J, Nielsen KF, Krause TG, et al. (2021) Vaccine effectiveness after $1^{\text {st }}$ and $2^{\text {nd }}$ dose of the BNT162b2 mRNA Covid-19 Vaccine in long-term care facility residents and healthcare workers-a Danish cohort study. MedRxiv.

3. Thomas K, Gelles D, Zimmer C (2020) Pfizer's early data shows vaccine is more than $90 \%$ effective. The New York Times, USA.

4. Shaker M, Abrams EM, Greenhawt M (2021) A cost-effectiveness evaluation of hospitalizations, fatalities, and economic outcomes associated with universal versus anaphylaxis risk-stratified COVID-19 vaccination strategies. J Allergy Clin Immunol Pract.

5. Lamb YN (2021) BNT162b2 mRNA COVID-19 vaccine: First approval. Drugs 81(4): 495-501.

6. Kratz A, Huotari M, Hanemann T, Arcesati R (2020) Chinese FDI in Europe: 2019 update. A report by Rhodium Group (RHG) and the Mercator Institute for China Studies (MERICS).

7. Grimm CA (2021) Hospitals reported that the covid-19 pandemic has significantly strained health care delivery.

8. Walsh EE, Frenck R, Falsey AR, Kitchin N, Absalon J, et al. (2020) RNAbased COVID-19 vaccine BNT162b2 selected for a pivotal efficacy study. Medrxiv.

9. MJ EO, Toledo JD, Pfizer-BioNTech B, la primera vacuna ARNm contra la COVID-19, parece segura y eficaz.

10. COVID I, Hay SI (2020) COVID-19 scenarios for the United States. medRxiv.

11. Tran TNA, Wikle N, Albert J, Inam H, Strong ER, et al. (2021) Optimal SARS-CoV-2 vaccine allocation using real-time seroprevalence estimates in Rhode Island and Massachusetts. medRxiv.

12. Farham B (2021) COVID-19 vaccines-the magic bullet? South African Medical Journal 111(1): 3-3.

13. Janett S (2020) The effectiveness of the Swiss and Canadian antibiotic distribution system compared (Doctoral dissertation, Haute école de gestion de Genève).

14. Shimabukuro T, Nair N (2021) Allergic reactions including anaphylaxis after receipt of the first dose of Pfizer-BioNTech COVID-19 vaccine. JAMA 325(8): 780-781. 
15. Jackson LA, Anderson EJ, Rouphael NG (2020) An mRNA vaccine against SARS-CoV-2 - preliminary report. N Engl J Med 383(20): 19201931.

16. Zaki A, Boheemen SV, Bestebroer TM, Osterhaus ADME, Fouchier RAM, et al. (2012) Novel coronavirus-Saudi Arabia: human isolate. Int Soc Infect Dis 367(19): 1814-1820.

17. Centers for Disease Control and Prevention (CDC) (2003) Update: Outbreak of severe acute respiratory syndrome-worldwide, 2003. MMWR Morb Mortal Wkly Rep 52(12): 241-246.

18. World Health Organization (2003) Coronavirus never before seen in humans is the cause of SARS- update 31. The Organization, Geneva, Switzerland.

19. Peiris JS, Lai ST, Poon LL, Guan Y, Yam LY, et al. (2003) Coronavirus as a possible cause of severe acute respiratory syndrome. Lancet 361(9366): 1319-1325.

20. Dyer 0 (2020) Covid-19: Trump sought to buy vaccine developer exclusively for US, say German officials. BMJ 368: m1100.

21. Baden LR, El Sahly HM, Brandon E, Karen K, Sharon F, et al. (2020) Efficacy and Safety of the mRNA-1273 SARS-CoV-2 Vaccine. N Engl J Med 384(5): 403-416.

22. (2020) Department of Health and Human Services, Food and Drug Administration, Center for Drug Evaluation and Research (CDER), Center for Biologics Evaluation and Research (CBER). Enhancing the diversity of clinical trial populations - eligibility criteria, enrollment practices, and trial designs: guidance for industry.

23. Dufailu OA, Afriyie-Asante A, Bernard G, Kwabena DA, Helena $Y$, et al. (2021) COVID-19 in Africa: an ovarian victory? J Ovarian Res 14(1): 1.

24. Tan JB, Cook MJ, Logan P, Rozanova L, Wilder-Smith A, et al. (2021) Singapore's Pandemic Preparedness: An Overview of the First Wave of COVID-19. Int J Environ Res Public Health 18(1): 252.

25. Zhou F, Yu T, Du R, Fan G, Liu Y, et al. (2020) Clinical course and risk factors for mortality of adult inpatients with COVID-19 in Wuhan, China: A retrospective cohort study. Lancet 395(10229): 1054-1062.

26. Huang C, Wang Y, Li X, Ren L, Zhao J, et al. (2020) Clinical features of patients infected with 2019 novel coronavirus in Wuhan, China. Lancet 395(10223): 497-506.

27. Zhu N, Zhang D, Wang W, Li X, Yang B, et al. (2020) A Novel Coronavirus from Patients with Pneumonia in China, 2019. N Engl J Med 382(8): 727-733.

28. Guan WJ, Ni ZY, Hu Y, Liang WH, Ou CQ, et al. (2020) Clinical characteristics of coronavirus disease 2019 in China. N Engl J Med 382: $1708-1720$.

29. Chen N, Zhou M, Dong X, Qu J, Gong F, et al. (2020) Epidemiological and clinical characteristics of 99 cases of 2019 novel coronavirus pneumonia in Wuhan, China: A descriptive study. Lancet 395(10223): 507-513.

30. Wang D, Hu B, Hu C, Zhu F, Liu X, et al. (2020) Clinical characteristics of 138 hospitalized patients with 2019 novel coronavirus-infected pneumonia in wuhan, China. JAMA 323(11): 1061-1069.

31. Polack FP, Thomas SJ, Kitchin N, Absalon J, Gurtman A, et al. (2020) Safety and Efficacy of the BNT162b2 mRNA Covid-19 Vaccine. N Engl J Med 383(27): 2603-2615.

32. Anderson EJ, Rouphael NG, Widge AT, Jackson LA, Roberts PC, et al. (2020) Safety and Immunogenicity of SARS-CoV-2 mRNA-1273 Vaccine in Older Adults. N Engl J Med 383: 2427-2438.

33. Folegatti PM, Ewer KJ, Aley PK, Angus B, Becker S, et al. (2020) Safety and immunogenicity of the ChAdOx1 $\mathrm{nCoV}-19$ vaccine against SARSCoV-2: A preliminary report of a phase $1 / 2$, single-blind, randomised controlled trial. Lancet 396(10249): 467-478.

34. Ramasamy MN, Minassian AM, Ewer KJ, Flaxman AL, Folegatti PM, et al. (2020) Safety and immunogenicity of ChAdOx1 nCoV-19 vaccine administered in a prime-boost regimen in young and old adults (COV002): A single-blind, randomised, controlled, phase $2 / 3$ trial. Lancet 396(10267): 1979-1993.

\section{Your next submission with Juniper Publishers} will reach you the below assets

- Quality Editorial service

- Swift Peer Review

- Reprints availability

- E-prints Service

- Manuscript Podcast for convenient understanding

- Global attainment for your research

- Manuscript accessibility in different formats

( Pdf, E-pub, Full Tsext, Audio)

- Unceasing customer service

Track the below URL for one-step submission

https://juniperpublishers.com/online-submission.php 